\title{
KAJIAN FAKTOR PSIKOLOGI YANG BERPOTENSI MEMPENGARUHI KEBERHASILAN RUKYAT
}

\author{
Ridhokimura Soderi', Ahmad Izuddin ${ }^{2}$ \\ ${ }^{1}$ Alumni Mahasiswa S2 Ilmu Falak Univeristas Islam Negeri Walisongo \\ e-mail: kimuraridho@gmail.com \\ 2 Universitas Islam Negeri Walisongo Semarang \\ e-mail: izzuddin@walisongo.ac.id
}

\begin{tabular}{|l|l|l|}
\hline Diterima: 21-01--2020 & Direvisi: 16-05-2020 & Dipublish: 29-06-2020 \\
\hline
\end{tabular}

\begin{abstract}
The success factor in hilal is not only related to astronomical aspects. However, it is also closely related to perukyat's psychological itself. In psychology, experience is one aspect studied as a scientific study of behavior and mental processes. Psychology uses a systematic method to observe human behavior and draw conclusion from this observation. Some psychological aspects of the perukyat are vision, perception, attention, concentration, and experience. Thorndike's law effect theory states that if an action is followed by a satisfactory change in an environment, the possibility of that action to be repeated tends to increase. That experience is an ability to decide on something because of the knowledge that has been obtained previously. In everyday buman life, buman experience always forms a unity in certain patterns and configurations. The rukyat technique used by Inwanuddin is in line with psychological theories, namely rukyat before ghurub which aims to increase concentration, then many experiences also affect the subsequent results of rukyat. Some levels of experience obtained based on the data and results of the interval class calculation are: 1-5 times is less experienced, 6-10 times sufficient experience, 11-15 times experienced, 16-20 times very experienced.
\end{abstract}

Kata kunci: perukyat, psikologi, pengalaman rukyat hilal.

\section{PENDAHULUAN}

$F$ aktor keberhasilan melihat hilal tidak hanya berkaitan dari aspek astronomi saja. Tetapi juga erat kaitannya dengan psikologis perukyat itu sendiri. Psikologi diartikan sebagai studi ilmiah yang mempelajari proses perilaku dan proses mental, ilmu ini menggunakan metode yang sistematis dalam mengamati perilaku manusia untuk menarik kesimpulan dari pengamantan tersebut, Dalam kehidupan manusia sehari-hari pengalaman manusia selalu membentuk satu kesatuan dengan pola tertentu.

Pengetahuan menjadi lengkap ketika sains dan psikologi telah menjadi sebuah pemahaman tertentu. Teori Law Effect yakni jika sebuah tindakan diikuti oleh sebuah perubahan yang memuaskan dalam lingkungan, maka kemungkinan tindakan itu diulang kembali dan akan semakin meningkat. Sebaliknya, jika sebuah tindakan diikuti oleh perubahan yang tidak memuaskan, maka tindakan tersebut tidak dilakukan lagi. Dengan kata lain, konsekuensi dari perilaku sesorang memainkan peran penting terhadap perilaku-perilaku dikemudian hari.

Saat ini kesaksian hilal tidak bisa dipercaya hanya melalui pengakuan saja. Objek hilal yang sangat tipis dan sering juga dipengaruhi oleh kondisi langit yang mendung membuat hilal sulit untuk 
diamati. Menurut Thomas Djamaluddin, kriteria ketinggian hilal jangan hanya berdasarkan pemahaman dari dalil-dalil syari'i dan laporan dari kesaksian perukyat semata, tetapi harus berdasarkan landasan ilmiah astonomis agar tidak menjadi bahan 'bully' para komunitas astronomi internasional terhadap kriteria yang di gunakan di Indonesia. (Djamaluddin, 2010)

Masalah-masalah yang menghambat dalam merukyat hilal secara visual yaitu kondisi cuaca, ketinggian hilal, elongasi, atmosfir, kualitas teleskop, kondisi psikologis perukyat. (Tono, 2007: 87)

Dalam hal ini kondisi psikologis juga menentukan seoarang perukyat itu sendiri, karena merukyat itu berhubungan langsung dengan panca indra manusia, psikologi mempelajari hal-hal yang berkaitan dengan perilaku manusia.

Dalam penelitian ini penulis menggunakan metode kualitatif, Penelitian kualitatif biasa disebut dengan penelitian interpretif atau penelitian lapangan. (Emzir, 2014: 2) Sumber data primer yaitu data yang dikumpulkan langsung oleh peneliti dari percobaan atau kegiatan lapangan yang dilakukan, data ini merupakan data original dan baru pertama kali diperoleh. (Timotius, 2017: 69) Data primer diperoleh langsung oleh peneliti yaitu wawancara langsung terhadap Muhammad Inwanuddin, wawancara langsung dan LFNU Gresik. Sumber data sekunder yaitu data yang lebih dahulu dikumpulkan dan laporkan oleh orang luar diri penyidik itu sendiri, atau disebut dengan data dari tangan kedua. (Sukarhmad, 1990: 163) Literatur yang digunakan yaitu berkaitan dengan ilmu-ilmu falak, rukyat hilal, psikologi umum. Dalam permasalahan ini penulis mencoba mengangkat pene-litian dengan pendekatan ilmu psikologi.

\section{PENGERTIAN RUKYAT DAN HILAL}

\section{Rukyat}

Secara bahasa rukyat berasal dari kata $r a^{\prime} a$, yara, ra'yan, wa ru'yatan yang bermakna melihat, mengerti, menyangka dan mengira. (Munawwir, 1984: 494-495) Rukyat artinya observasi atau mengamati benda langit, rukyatul hilal adalah kegiatan mengamati pada saat matahari terbenam, menjelang bulan baru Qamariyah. (Muhyiddin, 2005) Rukyat adalah kegiatan melihat hilal dengan mata, baik tanpa alat maupun dengan alat. (Lembaga Falakiyah PBNU, 2006)

Rukyat yang bermakna pengamatan hilal awal bulan baru merupakan kegiatan yang sudah dilakukan oleh umat Islam sejak masa Nabi SAW hingga saat ini. Umat Islam pada masa itu dalam penentuan awal bulan Qamariah berdasarkan pada pengamatan hilal jika tidak terlihat hilal maka digenapkan manjadi 30 hari, cara ini yang umat Islam yakini sebagai cara yang paling sesuai dengan tuntunan Rasulullah SAW, dan pemahaman seperti ini juga yang dianut oleh para jumhur ulama termasuk empat Imam Mazhab (Syafi'i, Hambali, Hanafi dan Maliki). (Muhammad, 2013: 104)

Rukyat seperti ini adalah rukyat yang pernah dilakukan oleh Rasulullah SAW dan para sahabat pada zaman itu "Berpuasalah kalian karena melihat hilal dan berbukalah kalian karena melihat hilal". Hal ini membuat ada umat yang kurang setuju dengan 
perhitungan ahli ilmu falak sekarang ini. Menurut mereka itu hanyalah menambah-nambah syariat yang telah dilakukan oleh Rasulullah SAW dan para sahabat. Dengan demikian, rukyat dengan pengamatan langsung ini yang memberikan solusi terhadap kebingungan umat dalam menentukan awal bulan Qamariyah. untuk itu pergantian bulan baru berdasarkan pada terlihat atau tidaknya dengan mata telanjang. (Taufiqurrahman, 2010: 32)

\section{Dalil Rukyat.}

a. QS Al Baqarah 185.

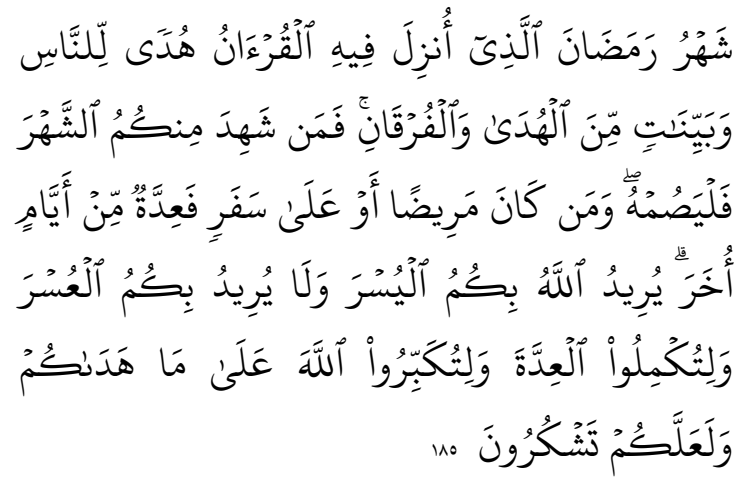

"Bulan ramadhan adalah (bulan) yang di dalamnya yang diturunakan alQuran, sebagai petunjuk bagi umat manusia dan penjelasan-penjelasan mengenai petunjuk itu dan pembeda (antara yang benar dan bathil). Karena itu barang siapa di antara kamu ada di bulan itu, maka berpuasalah. Dan barang siapa siapa sakit atau dalam perjalanan (dia tidak berpuasa) maka (wajib menggantinya), sebanyak hari yang ditinggalkannya itu, pada hari-hari lain. Allah menghendaki kemudahan bagimu, dan tidak menghendaki kesulitan bagimu. Hendakalah kamu mencukupkan bilangannya dan meng- agungkan Allah atas petunjuk-Nya yang diberikan kepadamu, agar kamu bersyukur. (QS. Al Baqarah [2]: 185)

b. Hadis Riwayat Muslim.

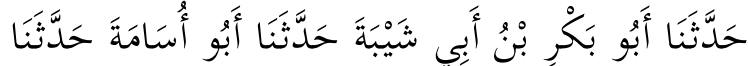

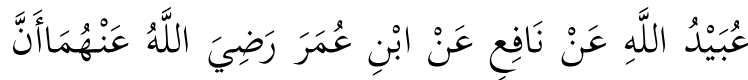

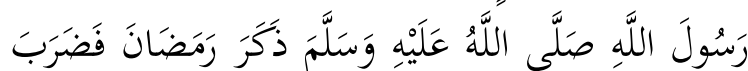

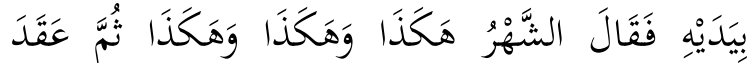

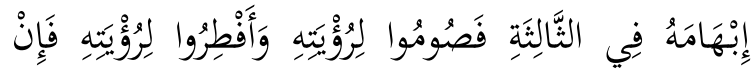

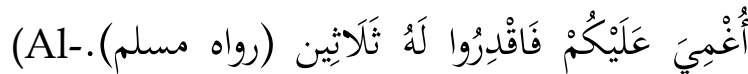

Hajjaj, n.d.)

"Abu Bakar bin Abi Syaibah bercerita kepada kami Abu Usamah bercerita kepada Kami Ubaidillah dari Nasi' bin Umar RA bahwa Rasulullah SAW menuturkan masalah bulan Ramadan sambil menunjukkan kedua tangannya kemudian berkata, bulan itu seperti ini, seperti ini, seperti ini, kemudian menelungkupkan ibu jarinya pada saat gerakan yang ketiga. Maka berpuasalah kalian karena melihat hilal dan berbukalah karena melihat hilal pula, jika terhalang oleh awan terhadapmu maka genapkanlah tiga puluh hari." (HR. Muslim)

c. Hadis Riwayatal-Bukhari.

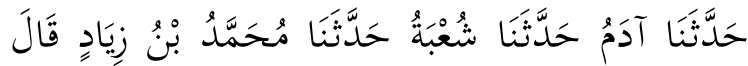

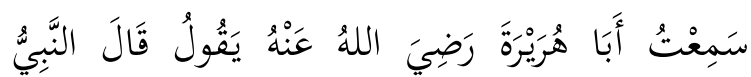

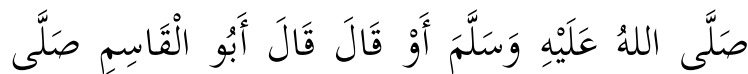

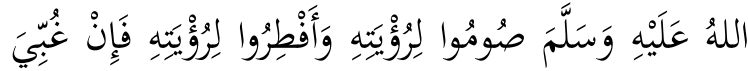

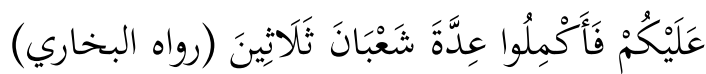
(Al-Bukhari, n.d.) 
"Adam bercerita kepada kami Syu'bah bercerita kepada kami Muhammad bin Ziyad dia berkata saya menedengar Abu Hurairah dia berkata Nabi SAW bersabda atau berkata Abu Qasim SAW berpuasalah kamu karena melihat hilal dan berbukalah karena melihat hilal pula, jika hilal terhalang oleh awan terhadapmu maka genapkanlah bulan Sya'ban tiga puluh hari." (HR. al-Bukhari).

Disini ahli hukum dapat mengatakan bahwa hadis ini menunjukan kepada suatu tujuan dan sekaligus menjelaskan cara (sarana). Tujuan yang dimaksud dalam hadis itu jelas, yaitu melaksanakan puasa ramadhan secara keseluruhan sehingga tidak ada satu hari pun yang tertinggal atau tidak berpuasa satu hari pada bulan lain seperti syakban atau syawal. Hal itu dilakukan dengan meneteapkan masuk atau berakhirnya bulan melalui sarana (cara) yang dapat dilakukan oleh kebanyakan orang tanpa menimbulkan kesukaran dan kesulitan bagi mereka dalam melaksanakan agamanya. (Qaradhawi, 2012: 126)

\section{Hilal}

a. Hilal Secara Bahasa.

Ibnu Manzur dalam Lisan al'Arabnya menyebutkan definisi hilal dari segi bahasa. Antara lain hilal merupakan awal atau sebagian yang tampak (yahillu) oleh manusia. Makna hilal juga sesuatu yang terlihat pada dua atau tiga malam pertama, atau sesuatu yang telah terbentuk (yuhajjir) seperti hilal. Hilal juga bermakna sesuatu yang bercahaya saat malam. (Rakhmadi, 2014: 45)

\section{b. Hilal Secara Astronomi.}

Hilal secara astronomi adalah bagian dari bulan yang cahayanya terlihat dari bumi saat setelah matahari terbenam yang didahului terjadinya ijtimak atau konjungsi. Bulan tidak memancarkan cahaya sendiri, bentuk cahaya hilal adalah pantulan dari sinar matahari. Bentuk bulan beubah-ubah dari hari ke hari, namun pada dasarnya bentuk bulan tidak berubah, hal ini disebakan oleh peredarannya.(1) Rotasi (2) Revolusi (3) Gerakan bersama bulan dan bumi mengelilingi matahari.

Proses terjadinya hilal secara astronomi adalah rangkaian fase-fase bulan yaitu ketika bulan berada pada fase wane yang disebut juga dengan proses ijtimak atau konjungsi. Maka saat itu, hilal dinyatakan telah wujud meski terkadang tidak telihat oleh mata. (Rakhmadi, 2014: 46)

Hilal adalah bagian dari bulan yang kemunculannya pada malam kesatu, kedua, dan ketiga pada awal bulan setelah terjadi ijtima', dan merupakan salah satu fenomena alam yang sangat menarik dalam penentuan waktu dan pergantian awal bulan Qamariah. (Zaman, 2015)

Hilal digunakan sebagai penentu waktu ibadah. Perubahan yang jelas dari hari ke hari menyebabakan bulan dijadikan penentu waktu ibadah yang baik. Tidak hanya umat Islam yang menggunakan bulan sebagai penentu waktu kegiatan keagamaan. Umat Hindu juga menggunakan bulan mati sebagai penentu hari nyepi. Umat Budha menggunakan bulan purnama sebagai waktu waisak. Umat Kristiani menggunakan purnama pertama 
setelah vernal equinox (21 maret) sebagai penentu hari Paskah. (Zaman, 2015)

\section{Dalil QS : Al Baqarah 189}

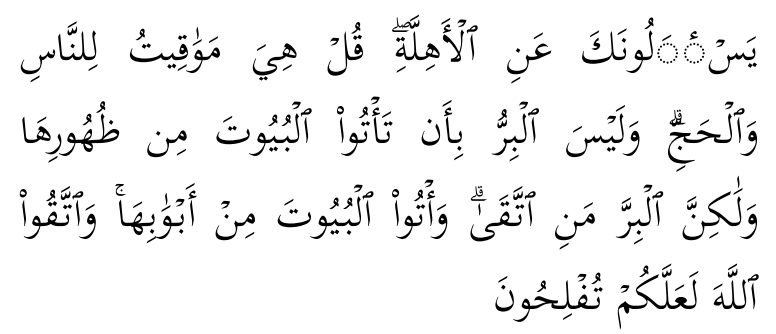

"Mereka bertanya kepadamu (Muhammad) tentang bulan sabit. Katakanlah, "Bulan sabit itu adalah tanda-tanda waktu bagi manusia dan (bagi ibadat) haji; Dan bukanlah kebajikan memasuki rumah-rumah dari belakangnya, akan tetapi kebajikan itu ialah kebajikan orang yang bertakwa. Dan masuklah ke rumah-rumah itu dari pintupintunya; dan bertakwalah Allah agar kamu beruntung."(QS. Al Baqarah [2]: 189)

\section{TINJAUAN PSIKOLOGIS PE-RUKYAT}

Psikologi diartikan sebagai studi ilmiah yang mempelajari proses perilaku dan proses mental, ilmu ini menggunakan metode yang sistematis dalam mengamati perilaku manusia untuk menarik kesimpulan dari pengamatan tersebut, tujuan ilmu ini adalah menggambarkan dan menjelaskan perilaku manusia. (Laura, 2016: 9)

Psikologi sebagai ilmu tentang perkembangan dan pikiran manusia. Pengetahuan menjadi lengkap ketika sains dan psikologi telah menjadi sebuah pemahaman tertentu. Terdapat dua katagori dalam psikologi yaitu Istilah materi dan ruh. Materi adalah segala hal yang dapat diindra oleh manusia dan segala hal yang tidak dapat diindra oleh manusia sebagai ruh. Pengetahuan tentang segala hal itulah yang disebut psikologi, dan pengetahuan yang tidak melalui pemahaman atau bukan pula melalui pengindraan tetapi melalui pengilhaman disebut jenis pengetahuan esoterisme. (Inayat, 2000: 13)

\section{Penglihatan}

Penglihatan adalah indra yang paling banyak diteliti ketimbang semua indra yang lain mata lebih banyak infromasi mengenai dunia eksternal kita peroleh melalui mata dibandingkan dengan organ panca indra lainya. (Carol, 2007: 200)

Rangsangan dari penglihatan manusia adalah cahaya, cahaya yang datang dari berbagai sumber baik itu matahari ataupun lampu yang kemudian dipantulkan dalam wujud gelombang. Kareteristik dari gelombang ini memengaruhi tiga dimensi psikologis dari dunia penglihatan manusia. Pertama hue, yaitu dimensi warna pada penglihatan mata manuisa. Kedua Brihgtnes yaitu dimensi intensitas cahaya pada penglihatan yang dipantulkan oleh sebuah benda. Ketiga saturation yaitu dimensi kompleksitas cahaya pada peng-lihatan, seberapa lebar atau seberapa sempit jangkuan gelombang cahaya. (Carol, 2007: 202)

Meskipun mata sering dibandingkan dengan kamera sistem penglihatan mata tidak seperti kamera yang merupakan alat perekam pasif. Berbeda dengan mata saraf-saraf dalam sistem penglihatan mata secara aktif 
membuat gambar dari luar dengan cara mendeteksi. (Carol, 2007: 202).

Sistem kamera, cahaya masuk kedalam film pada kamera. Meskipun kamera alat perekam yang pasif kamera bermanfaat untk memahai optic pada mata, Bruce dan Green menunjukan sejumlah perbedaan penting:

1. Jika dinilai berdasarkan standar yang sama seperti kamera, kualitas mata lebih baik.

2. Jika kamera yang bergerak sebanyak mata maka akan menghasilkan gambar-gambar yang kabur. (Richard, 2012: 26)

Mata lebih sempurna dari pada alat kamera karena pupil dan akomodasi berkerja secara bersamaan dan secara otomatis, sedangkan pada alat kamera harus diatur lebih dahulu. Selain itu, air mata selalu membersihkan kotoran kotoran yang masuk kedalam mata secara otomatis. (Fudyartanta, 2011: 198)

Para psikolog menemunkan indra-indra manusia sangat peka, jika seseorang memiliki kemam-puan pengindraan yang normal maka dapat melihat cahaya lilin dalam malam dari jarak 30 mil, dan juga dapat mendengar detak jantung dalam ruangan yang sunyi. (Carol, 2007: 197)

\section{Persepsi}

Persepsi adalah proses yang dijalankan otak untuk menafsirkan informasi sensorik mengubahnya menjadi gambar tentang dunia luar, melalui persepsi, otak berusaha mengartikan kumpulan rangsangan sensorik yang menimpah organ sensorik kita. (Jefrey, 2017: 212)
Persepsi, merupakan kegiatan menyusun informasi dari organ-organ sensorik menjadi suatu keseluruhan yang bisa kita pahami. (David, 2004: 77)

Menurut Durie 2005, persepsi adalah nilai tambah yang diberikan oleh otak yang terorganisasi pada data panca indra, persepsi bukan sekedar "palet sensasi", atau melibatkan ingatan pengalaman masa lalu tetapi persepsi merupa-kan tingkat pemrosesan yang lebih tinggi, prosesnya dimulai dengan energi fisik yang merangsang organ panca indra yakni cahaya dalam kasus penglihatan dan gelombang suara dalam kasus pendengaran. Persepsi dan diakhiri dengan otak yang menginterpretasikan atau menafsirkan infromasi yang diterima organ pengindraan.

Syarat terjadinya persepsi pada diri seseorang yaitu adanya alat indra yang berfungsi dengan baik, rangsangan yang diterima oleh seseorang melalui alat indra atau reseptor (penerima) akan dibawa ke pusat saraf yaitu otak sehingga terjadilah proses persepsi. (Atnaja, 2012: 62)

Menurut Davidoff, persepsi dapat terjadi ketika rangsangan diterimnya oleh seseorang yang bersangkutan. Rangsangan yang ditangkap oleh panca indra diinterpretasikan oleh penerima rangsangan tersebut sehingga dapat menyadari dan mengerti tentang apa yang telah dilihatnya. (Atnaja, 2012: 63)

Proses terjadinya persepsi yaitu pertama suatu objek akan menimbulkan rangsangan terhadap panca indra atau reseptor seseorang. Proses ini disebut dengan proses fisik. Kedua rangsangan yang diterima oleh 
panca indra kemudian dihantarkan oleh saraf sensoris ke otak, bagian ini disebut dengan proses proses fisiologis. Ketiga, setelah proses rangsangan dihantarkan ke otak kemudian seseorang baru dapat menyadari ada sesuatu yang telah diterimanya melalui panca indra tersebut. Proses kesadaraan yang terjadi pada seseoarng itu dinamakan proses psikologis yang merupakan proses terakhir dari persepsi. (Atnaja, 2012: 63)

Lebih lanjut ada yang namanya hukum gesalt yaitu cara manusia mengkelompokam apa yang telah dipersepsikannya atau hukum pragnanz dalam bahasa jermannya adalah kesadaran. Yang termasuk di dalam hukum gesalt ini adalah 'law of similiirt' (hukum kesamaan), 'law of proximity' (hukum kedekatan) dan 'law of contiguitiy' (hukum keuutuhan).

Setiap saat ada ratusan, mungkin ribuan rangsangan yang tertangkap oleh semua panca indra. Tentunya seseorang tidak mampu menyerap semua rangsangan yang ada disekitar kita sekaligus, karena keterbatasan daya serap dari persepsi seseorang. Maka seseorang terpaksa memusatkan perhatian kita pada satu atau dua objek saja. Kesiapan mental seseorang dalam menghadapi suatu rangsangan yang akan timbul dengan cara tertentu. (Srlito, 2014: 95-100)

\section{Atensi}

Atensi adalah proses memfokuskan pada objek lingkungan dari berbagai infrormasi yang dapat di identifikasikan atensi selektif yaitu pemokusan pada aspek pengalaman tertentu yang menga-baikan aspek lain. (Laura, 2016: 141)

Atensi pada pemrosesan selektif mengarahkan perhatian kita pada suatu hal, dengan kata lain merupankan suatu proses kesa-daran. Atensi merupakan proses yang mengendalikan infromasi secara sadar. Oleh karena itu atensi juga dapat dikonsepkan sebagai proses penyaringan. Atensi visual yaitu mencari informasi yang telah dipelajari, teori ini menggabungkan fitur-fitur berbeda dari suatu objek (misalnya warna dan bentuk). Hal ini berguna bagi seseorang untuk menemukan objek di latar objek lainnya. (Jonathan, 2012: 36-37)

Atensi visual terfokus, menurut Driver yaitu peristiwa kehidupan sehari hari yang bercampur terhadap banyak objek yang dapat kita persepsi secara utuh, jadi atensi diperlukan untuk menyeleksi objek-objek yang dimaksud untuk diproses lebih lanjut. salah satu mekanismenya melalui gerakan-gerakan mata yang dapat memfokuskan ke objek tertentu sehingga mendapatkan ketajaman mata yang lebih baik dalam menyeleksi objek tertentu. (Richard, 2012: 264)

\section{Konsentrasi}

Konsentrasi adalah mengelompokkan atom-atom halus pada objek yang nampak pada mata sehingga dapat membentuk dalam pikiran suatu gambar atau objek sesuai yang dilihat oleh mata. Selama seseorang mengobservasi suatu objek dan sepanjang kapasitas memorinya cukup maka segala objek bisa 
dimunculkan di depan mata sesuai dengan yang diper-sepsikanya kapan pun diinginkan. Apabila seseorang memikirkan hal tertentu dan tidak dapat mengingatnya mungkin pikiran seseorang tidak kuat atau kurang-nya observasi yang dilakukan. Seseorang yang melakukan observasi dengan pengamatan yang mendalam akan memberikan sensasi yang kuat dalam pikiran untuk berkonsenstarsi. Setiap objek yang dilihat oleh mata akan disimpan dalam memori, tetapi pada saat itu apa yang dilihat objek di dalam memori itu masih berupa kepingankepingan objek jika seseorang mengingatnya dengan kuat maka setiap kepingan akan menjadi objek yang utuh. Konsentrasi bisa dibagi menjadi tiga tingkatan yaitu perintah, aktivitas, dan kendali. Pertama perintah, memerintah pikiran agar aktif dan meciptakan objek yang diinginkan, kedua pikiran, membawa perintah tersebut dengan menyusun objek berdasarkan kemampuanya, dan ketiga kendali untuk menahan agar objek dapat terbentuk dalam pikiran. (Inayat, 2000: 117-124)

\section{Pengalaman.}

a. Thorndike Edward Lee

Thorndike Edward Lee adalah psikolog berkebangsaan Amerika Thorndike menyatakan, perilaku belajar manusia ditentukan oleh rangsangan yang ada di lingkungan sehingga menimbulkan respon secara refleks. Rangsangan yang terjadi pada sebuah perilaku akan mempengaruhi perilaku selanjutnya. Thorndike telah mengembangkan teori Law Effect, yakni jika sebuah tindakan diikuti oleh sebuah perubahan yang memuaskan dalam lingkungan, maka kemungkinan tindakan itu akan diulang kembali dan akan semakin meningkat. Sebaliknya, jika sebuah tindakan diikuti oleh perubahan yang tidak memuaskan, maka tindakan tersebut tidak dilakukan sama lagi. Dengan kata lain, konsekuensi dari perilaku seseorang akan memainkan peran penting terhadap perilaku-perilaku yang akan datang. Menurut Thorndike, belajar adalah sebuah proses interaksi antara stimulus dan respon. Stimulus adalah yang dapat merangsang terjadinya kegiatan belajar seperti pikiran, perasaan, atau hal-hal lain yang dapat ditangkap melalui panca indra. Sedangkan respon yaitu reaksi yang dimunculkan seseorang ketika belajar, yang juga dapat berupa pikiran, perasaan, atau gerakan dan tindakan. Maka menurut Thorndike, perubahan tingkah laku akibat dari kegiatan belajar itu dapat berwujud konkret yaitu yang dapat diamati, atau yang tidak konkret yaitu yang tidak dapat diamati.

\section{b. Wisnu Buntaran}

Pengalaman itu suatu bentuk kemampuan kita dalam memutuskan suatu hal karena adanya ilmu yang sudah kita dapatkan sebelumnya. Pengalaman itu dipelajari dari segi perilaku, karena perilaku dapat dipelajari dalam psikologi. Dalam kehidupan manusia sehari-hari pengalaman manusia selalu membentuk satu kesatuan dengan pola tertentu. (Atnaja, 2012: 301) 


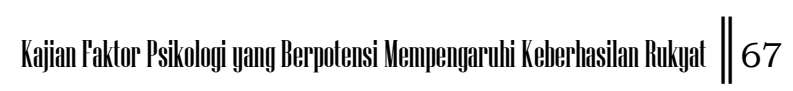

c. Muhammad Inwanuddin

Muhammad Inwanuddin atau lebih dikenal ustad Inwanuddin adalah perukyat dari LFNU bukit condrodipo gresik. Lahir di Gresik 17 September 1976 M, terlahir dari pasangan $\mathrm{H}$. Muhammad Chudlari dan Ibu $H$. Munafasah. (Inwanuddin, 24 Januari 2019)

\section{Gambar I}

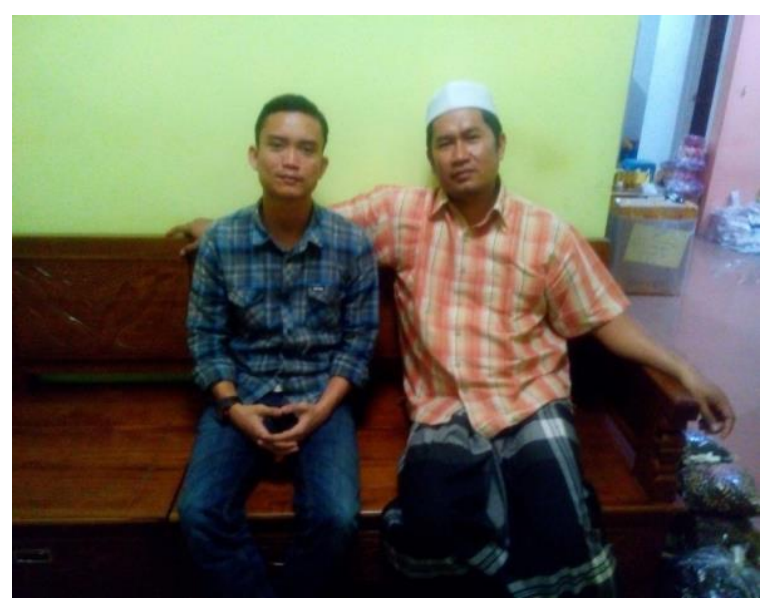

(Foto Bersama Muhammad Inwanuddin. Perukyat LFNU Gresik)

Muhammad Inwanuddin pertama kali melakukan rukyatul hilal saat duduk di bangku kelas menengah ke atas, dalam melakukan kegiatan rukyatul hilal. Muhammad Inwanuddin melakukan observasi di Bukit Condrodipo Gresik. Hilal yang berhasil di lihat oleh Inwanuddin selama ini menggunakan mata telanjang, selama merukyat Muhammad Inwamuddin tidak pernah meng-gunakan alat bantu atau teleskop. (Inwanuddin, 24 Januari 2019)
Tabel I

Hasil Rukyat Muhammad Inwanuddin

\begin{tabular}{|c|c|c|}
\hline Pengamat & $\begin{array}{l}\text { Tgl/Bulan/Tahu } \\
\text { n }\end{array}$ & Tinggi Hilal \\
\hline \multirow{9}{*}{$\begin{array}{l}\text { Muhamma } \\
\text { d } \\
\text { Inwanuddi } \\
\text { n }\end{array}$} & $\begin{array}{l}\text { Ramadhan } \\
1429 / 1 / 9 / 2008\end{array}$ & $\begin{array}{l}05^{\circ} 23^{\prime} \\
44,84^{\prime \prime}\end{array}$ \\
\hline & $\begin{array}{l}\text { Dzulhijjah } \\
1430 / 18 / 112009\end{array}$ & $05^{\circ} 41^{\prime} 29^{\prime \prime}$ \\
\hline & $\begin{array}{l}\text { Ramadhan } \\
1431 / 11 / 8 / 2010\end{array}$ & $02^{\circ} 17^{\prime} 13^{\prime \prime}$ \\
\hline & $\begin{array}{l}\text { Ramadhan1432/ } \\
\text { 1/8/2011 }\end{array}$ & $06^{\circ} 36^{\prime} 24^{\prime \prime}$ \\
\hline & $\begin{array}{l}\text { Dzulhijjah } \\
1432 / 28 / 10 / 201 \\
1\end{array}$ & $06^{\circ} 16^{\prime} 17^{\prime \prime}$ \\
\hline & Syawal 1435 & $3^{\circ} 00^{\prime} 53.37^{I I}$ \\
\hline & Ramadhan 1435 & $10^{\circ} 50^{\prime} 48.66^{I}$ \\
\hline & Shafar 1436 & $9^{\circ} 48^{\prime}$ \\
\hline & Muharram 1436 & $4^{\circ} 20^{\prime}$ \\
\hline \multirow{7}{*}{$\begin{array}{l}\text { Muhamma } \\
\mathrm{d} \\
\text { Inwanuddi } \\
\mathrm{n}\end{array}$} & $\begin{array}{l}\text { Dzulhijjah } \\
1435 / 25 / 9 / 2014\end{array}$ & $11^{\circ} 09^{\prime} 05.80^{\mp}$ \\
\hline & $\begin{array}{l}\text { Ramadhan } \\
1436 / 17 / 6 / 2015\end{array}$ & $09^{\circ} 07^{\prime}$ \\
\hline & $\begin{array}{l}\text { Syawal } \\
1436 / 16 / 7 / 2015\end{array}$ & $2^{\circ} 06^{\prime} 24^{ \pm}$ \\
\hline & $\begin{array}{l}\text { Ramadhan } \\
1437 / 5 / 6 / 2016\end{array}$ & $3^{\circ} 53^{\prime} 45^{\prime \prime}$ \\
\hline & $\begin{array}{l}\text { Syawal } \\
1437 / 5 / 7 / 2016\end{array}$ & $11^{\circ} 20^{y} 09^{m}$ \\
\hline & $\begin{array}{l}\text { Ramadhan } \\
1438 / 20 / 5 / 2017\end{array}$ & $8^{\circ} 6^{\prime}$ \\
\hline & $\begin{array}{l}\text { Syawal } \\
1438 / 24 / 6 / 2017\end{array}$ & $2^{\circ} 49^{\prime} 22^{m}$ \\
\hline
\end{tabular}




\begin{tabular}{|l|l|l|}
\hline & $\begin{array}{l}\text { Dzulhijjah } \\
1438 / 22 / 8 / 2017\end{array}$ & $6^{\circ} 35^{\prime} 52^{\text {m }}$ \\
\cline { 2 - 3 } & $\begin{array}{l}\text { Muhamrram } \\
1439 / 20 / 9 / 2017\end{array}$ & $1^{\circ} 45^{\prime} 03^{\text {I }}$ \\
& & \\
\hline
\end{tabular}

Sebelum merukyat Inwanuddin selalu berwudhu dan bertawashul kepada guru-gurunya, hal ini dikatakan bahwa untuk merukyat perlu hati dan diri yang suci sebelum melakukan rukyatul hilal. Memang tidak kajian ilmiah bahwa berwudhu dan bertawashul sebelum merukyat akan membuat perukyat berhasil dalam mengamati hilal, tetapi ritual seperti itu yang selalu dilakukan oleh Muhammad Inwanuddin sebelum melakukan rukyatul hilal, karena untuk merukyat perlu hati dan diri yang suci sebelum melakukan rukyatul hilal. (Inwanuddin, Januari 2019)

Kemudian ada teknik yang berkaitan dengan faktor psikologis yang dilakukan oleh Muhammad Inwanuddin dalam melakukan pengamatan hilal. Teknik rukyat yang dilakukan yaitu mengamati hilal sebelum matahari terbenam Teknik ini dilakukan ketika cahaya matahari tidak terlalu terang dan tidak terlalu menyilaukan yaitu 5 - 10 menit sebelum terbenam, menurut Muhamamd Inwanuddin hal ini bertujuan untuk berkonsentrasi penuh dan mempermudah mendapatkan posisi hilal jadi ketika ghurub pengamat langsung bersaksi saja jika memang hilal terlihat karena posisi hilal sudah diikuti dari sebelum matahari terbenam. Membidik hilal sebelum Matahari terbenam tetap menggunakan data hisab yang telah dihisab sebelumnya. (Inwanuddin, Januari 2019).
Menurut Abdul Muid sebagai pengurus LFNU gresik mengatakan bahwa menyakini terhadap hasil rukyat Muhamad Inwanuddin karena tidak hanya merukyat di tiga bulan penting saja, (Ramadhan, Syawal, Dzulhijjah), tetapi merukyat setiap awal bulan hijriah bersama tim LFNU Gresik di Bukit Condrodipo jadi sudah mempunyai pengalaman yang baik dalam merukyat. Faktor yang ikut berperan dalam mempengaruhi pengamat itu sendiri yaitu pengalaman, pengalaman dipelajari dari segi perilaku, pengalaman itu suatu bentuk kemampuan kita dalam memutuskan suatu hal karena adanya ilmu yang sudah kita dapatkan sebelumnya. (Muid, Januari 2019)

\section{Gambar II}

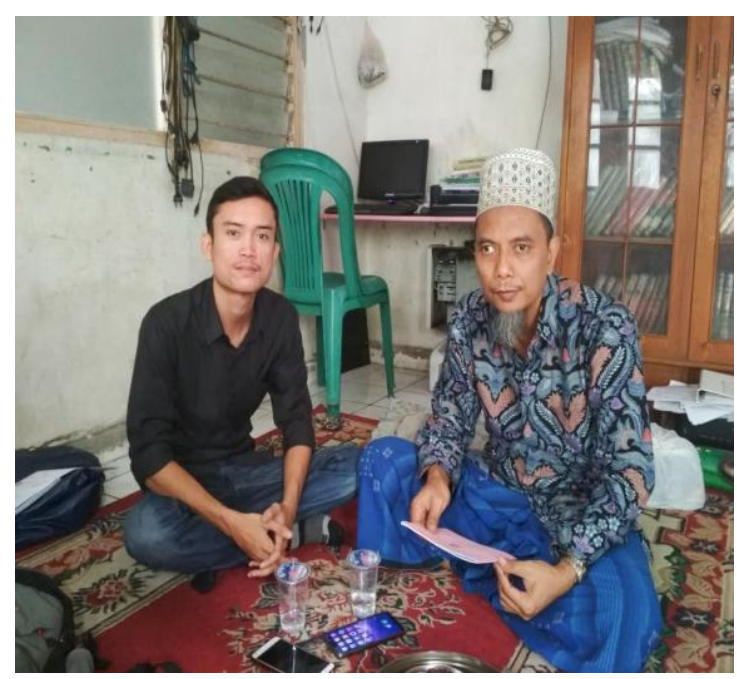

(Foto bersama Abdul Miud, Pengurus LFNU Gresik)

Jika dilihat dari data kesaksian dari Muhammad Inwanuddin bahwa pertama kali diterima kesaksiannya oleh pemerintah yaitu ketinggian hilal $05^{\circ} 23^{\prime} 44.84^{\prime \prime}$, ini menunjukan bahwa hilal yang dilihat oleh Muhamad Inwanuddin ditahun 2008 ketinggiaan- 


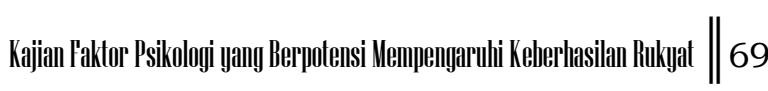

nya sudah memenuhi syarat kriteria, bukan tidak mungkin hal ini memengaruhi keberhasilan dari rukyat selanjut-nya.

Banyak perukyat yang terlalu fokus pada data ketinggian hilal pada saat magrib, padahal bulan itu juga bergerak terbenam, jadi ketika merukyat sulit untuk melihat hilal karena terpaku pada data awal, berbeda dengan cara Muhammad Inwanuddin merukyat yaitu dengan cara mengikuti pergerakan hilal, misalkan ketinggian 5 derajat saat magrib tetapi saat hilal mulai terbenam dan ketika sudah 2 derajat baru terlihat. (Muid, Januari 2019)

Jika dilihat secara teori psikologi teknik rukyat yang dilakukan Muhammad Inwanuddin tersebut sejalan dengan teori atensi yaitu proses memfokuskan pada aspek pengalaman tertentu dengan mengabaikan aspek lain, kemudian sejalan dengan teori kosenstrasi yaitu seseorang yang melakukan observasi dengan pengamatan yang mendalam akan memberikan tekat yang kuat dan pikiran yang kokoh, setiap objek yang dilihat oleh mata akan disimpan dalam memori otak.

Penulis juga akan mencari formulasi tingkat pengalaman dalam rukyatul hilal. Menggunakan sampel dari hasil rekap kementiran agama RI hilal yang termati di Indonesia dari tahun 1962.
Tabel II.

Nama Perukyat.

\begin{tabular}{|c|c|}
\hline Nama Perukyat & $\begin{array}{l}\text { Hilal Teramati } \\
\text { (kali) }\end{array}$ \\
\hline $\begin{array}{l}\text { KH. Ahmad } \\
\text { Izzuddin }\end{array}$ & 1 \\
\hline H. Moch Cholil & 3 \\
\hline M. Labib & 3 \\
\hline $\begin{array}{l}\text { KH. Ahmad } \\
\text { Martuni } \\
\text { Amrullah } \\
\end{array}$ & 6 \\
\hline $\begin{array}{l}\text { H. Abdullah bin } \\
\text { Azhari }\end{array}$ & 9 \\
\hline Abdul Salam & 10 \\
\hline K. Makmur & 11 \\
\hline $\begin{array}{l}\text { Muhammad } \\
\text { Inwanuddin }\end{array}$ & 13 \\
\hline Abdul Hamid & 16 \\
\hline
\end{tabular}

Dari hasil data tersebut langkah selanjutnya untuk mendapatkan tingkat pengalaman penulis akan membuat kelas interval menggunakan Distribusi Frekuensi. Distribusi Frekuensi adalah suatu kegiatan menyusun suatu data dimulai dari terkecil sampai yang terbesar yang akan membagi banyak data ke dalam beberapa kelas. (Syofian, 2010: 6) Langkah-langkah membuat frekuensi adalah sebagai berikut :

a. Pertama urutkan data dari yang terkecil sampai yang terbesar, data yang kita gunakan disini yaitu berdasarkan data tabel diatas. Datanya yaitu 1336910 111316

b. Kedua menghitung Jarak Atau Rentangan (R)

Rumusnya $(\mathrm{R})=$ Data Tertinggi - Data Terendah 16-1= 15

c. Ketiga menghitung Jumlah kelas (K) Rumusnya $(\mathrm{K})=1+3.3 \log (\mathrm{N})$ 


$$
\begin{aligned}
\mathrm{N} & =\text { Jumlah data } \\
\mathrm{K} & =1+3.3 \log \mathrm{N} \\
& =1+3.3 \log (9) \\
& =1+3.3 \times(0.95424251) \\
& =4.14=4
\end{aligned}
$$

d. Keempat menghitung Panjang kelas $(\mathrm{P})$

$$
\begin{aligned}
\mathrm{P} & =\mathrm{R} / \mathrm{K} \\
& =15 / 4 \\
& =3.75=4
\end{aligned}
$$

e. Kelima dari langkah diatas, didapatkan data sebagai berikut :

Banyak kelas $=4$

Panjang kelas $=4$

Dari hasil perhitungan diatas menggunakan distribusi frekuensi untuk mencari interval kelas maka didapatkan hasil sebuah tingkatan suatu pengalaman melihat hilal sebagai berikut:

Tabel III

Tabel Tingkat Pengalaman.

\begin{tabular}{|l|l|}
\hline $\begin{array}{l}\text { Kelas } \\
\text { Interval }\end{array}$ & Klasifikasi \\
\hline $1-5$ & $\begin{array}{l}\text { Kurang } \\
\text { Berpengalaman }\end{array}$ \\
\hline $6-10$ & $\begin{array}{l}\text { Cukup } \\
\text { Berpengalaman }\end{array}$ \\
\hline $11-15$ & Berpengalaman \\
\hline $16-20$ & $\begin{array}{l}\text { Sangat } \\
\text { Berpengalaman }\end{array}$ \\
\hline
\end{tabular}

\section{KESIMPULAN}

Dalam rukyatul hilal juga berpengaruh terhadap psikologi seorang perukyat, hal yang mempengaruhi perukyat adalah pertama penglihatan, penglihatan adalah panca indra pertama bagi manusia untuk menerima informasi dari dunia luar. Kedua, persepsi adalah proses suatu informasi yang di lihat oleh mata yang dikirimkan sinyal ke otak ketiga atensi yaitu suatu pemfokusan dalam suatu proses melihat. Keempat yaitu konsentrasi. Kelima pengalaman yaitu suatu bentuk kemampuan kita dalam memutuskan suatu hal karena adanya ilmu yang sudah kita dapatkan sebelumnya. Teknik rukyat yang dilakukan Inwanuddin sejalan dengan teori-teori psikologi yakni rukyat sebelum ghurub yang bertujuan untuk meningkatkan konsentrasi pada saat rukyatul hilal. Kemudian pengalaman rukyat yang bukan hanya sekedar di tiga bulan penting (Ramdhan, Syawal, Dzulhijjah) saja melainkan setiap awal bulan hijriah juga berpengaruh terhadap hasil rukyat itu sendiri hal ini bukan hanya sekedar halusinasi dari hasil rukyat sabelumnya. Jika di lihat Inwanuddin pertama kali melihat hilal dengan ketinggain hilal $05^{\circ} 23^{\prime} 44.84^{\prime \prime}$, ini menunjukan bahwa hilal yang dilihat oleh Muhamad Inwanuddin ditahun 2008 ketinggiaannya sudah memenuhi syarat kriteria, bukan tidak mungkin hal ini memengaruhi keberhasilan dari rukyat selanjutnya. Tingkatan pengalaman melihat hilal sebagai berikut, 1-5 kali adalah kurang berpengalaman, 6-10 kali cukup berpengalaman, 11-15 kali berpengalaman, 16-20 kali sangat berpengalaman. Jadi Muhammad Inwanuddin dalam hal ini berdasarakan catatan data tersebut termasuk yang berpengalaman ber-dasarkan perhitungan statistik. 


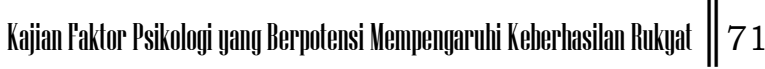

\section{DAFTAR PUSTAKA}

Al-Bukhari, A. A. M. bin I. (n.d.). Shahih Bukhari, hadis ke-1776. (Jilid II, ). Beirut: Dar al Fikr.

Al-Hajjaj, A. H. M. bin. (n.d.). Shahih Muslim,hadis ke-1796 (Jilid I). Beirut: Dar al Fikr.

Atnaja, P. P. (2012). Psikologilmum Dengan Perspektif Baru. Jogjakarta: Ar Ruzz Media.

Carol, W. C. (2007). Psikologi. Erlangga.

David, M. (2004). Pengantar Psikologi Lintas Budaya. Yogyakarta: Pustaka Pelajar.

Djamaluddin, T. (2010). Analisis Visibilitas Hilal Untuk Usulan Kriteria Tunggal di Indonesia. Retrieved from https:/ / tdjamaluddin.wordpress.co $\mathrm{m} / 2010 / 08 / 02 /$ analisis-visibilitashilal-untuk-usulan-kriteria-tunggaldi-indonesia

Emzir. (2014). Metodologi Penelitian Kualitatif Analisis Data. Jakarata: PT RajaGrafindo persada.

Fudyartanta. (2011). Psikologi Umum. Yogakarta: Pustaka Pelajar.

Inayat, K. (2000). Dimensi Spiritual Psikologi. Bandung: Pustaka Hidayah.

Jefrey, N. S. (2017). Psikologi Konsepsi dan Aplikasi. Bandung: Nusa Media.

Jonathan, L. J. (2012). Psikologi Kognitif. Erlangga.

Laura, K. a. (2016). Psikologi Umum, Sebuah Pandangan Apresiatif. Jakarta: Salemba.

Lembaga Falakiyah PBNU. (2006). Pedoman Rukyat dan Hisab Nahdhatul ulama. LEMBAGA FALAKIYAH PBNU.

Muhammad, N. (2013). Kalender Hijiriah Universal. Semarang: Rafi Sarana Prakasa.

Muhyiddin, K. (2005). Kamus Ilmu Falak. Jogjakarta: Buana Pustaka.

Munawwir, A. W. (1984). Al-Munawwir Kamus Arab Indonesia. Yogyakarta: PP Al-Munawwir Yogyakarta.

Qaradhawi, Y. Al. (2012). Hisab Bulan kamariah tinjuan syar'i tentang penetapan awal ramadhan. Syawal dan zulhijah. Yogyakarta: Suara Muhammadiyah.

Rakhmadi, B.-B. A. J. (2014). Problematika Penentuan Awal Bulan. Malang: Madani.

Richard, G. (2012). Psychology the Sience of Mind andBehavior. Yogyakarta: Pustaka Pelajar.

Srlito, S. W. (2014). Pengantar Psikologi umum. Depok: Raja Grapindo Persada.

Sukarhmad, W. (1990). Pengantar Penelitian Ilmiah Dasar, Metode dan Teknik. Bandung: Tarsito.

Syofian, S. (2010). Statistika Deskriptif Untuk Penelitian. Jakarta.

Taufiqurrahman. (2010). Ilmu Falak dan Tinjuan Matlak Global. Yogyakarta: MPKSDI.

Timotius, K. H. (2017). Pengantar Metodelogi Penelitian Pendekatan Manajemen Pengetahuan Untuk Perkembangan Pengetahuan. Yogyakarta: CV. Andi Offset. 


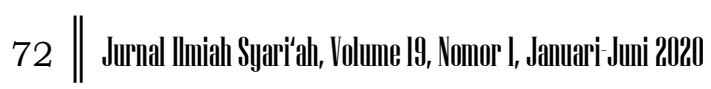

Tono, S. (2007). Mengkompromikan Hisab dan Rukyat. Jakarta: Amythas Publicita dan Center For Islamic Studies.

Zaman, Q. (2015). Memahami Makna Hilal Menurut Tafsir Al-Qur'an dan Sains. Universium, 9(1).

\section{Wawancara}

Inwanuddin, Perukyat LFNU Gresik, wawancara, 24 Januari 2019.

Muid, Pengurus LFNU Gresik, wawancara, Januari 2019. 